\title{
Awareness of and Attitudes toward Human Papillomavirus Vaccination among Adults in Korea: 9-Year Changes in Nationwide Surveys
}

\section{Jin-Kyoung Oh, $\mathrm{PhD}^{1,2}$ \\ Bo Yoon Jeong, $P h D^{2}$ \\ E Hwa Yun, PhD',2 \\ Min Kyung Lim, PhD ${ }^{1,2}$}

${ }^{1}$ Department of Cancer Control and Population Health, National Cancer Center Graduate School of Cancer Science and Policy, Goyang, ${ }^{2}$ Cancer Risk Appraisal $\mathcal{E}$ Prevention Branch, National Cancer Center, Goyang, Korea

\author{
Correspondence: Min Kyung Lim, $\mathrm{PhD}$ \\ Department of Cancer Control and \\ Population Health, National Cancer Center \\ Graduate School of Cancer Science and Policy \\ and Cancer Risk Appraisal \& Prevention Branch, \\ National Cancer Center, 323 Ilsan-ro, \\ Ilsandong-gu, Goyang 10408, Korea \\ Tel: 82-31-920-2016 \\ Fax: 82-31-920-2929 \\ E-mail: mickey@ncc.re.kr \\ Received April 11, 2017 \\ Accepted May 6, 2017 \\ Published Online May 10, 2017
}

\begin{abstract}
Purpose
Human papillomavirus (HPV) vaccination has been included in the National Immunization Program in Korea since 2016. We aimed to evaluate changes in the awareness of and attitudes toward HPV vaccination, among adults in Korea since the first introduction of the vaccines in 2007 .
\end{abstract}

\section{Materials and Methods}

A nationwide population-based survey was conducted in 2016 for 1,200 nationally representative Korean men and women; the data obtained were compared with the data from the nationwide survey conducted in 2007.

\section{Results}

A significant increase in the awareness of HPV infection (35.8\%) and vaccination (36.9\%) was observed in 2016 from $13.3 \%$ and $8.6 \%$ in 2007 , respectively. Willingness to be vaccinated against HPV decreased from $55.0 \%$ in 2007 to $25.8 \%$ in 2016 , and the proportion of respondents expressing uncertainty increased from $28.3 \%$ in 2007 to $43.3 \%$ in 2016. Only $12.1 \%$ of men and $22.0 \%$ of women knew about the free national HPV vaccination program for girls, launched in June 2016. Younger women, with higher income level, awareness of the HPV vaccine, and perception of the seriousness of infections had a higher willingness to be vaccinated. A high education level, awareness of HPV infection and vaccination, and perception of the seriousness of infection were positively associated with the willingness of respondents to vaccinate their daughters.

\section{Conclusion}

Raising the awareness of HPV infection and vaccination with appropriate knowledge is necessary for the successful implementation of the national HPV vaccination program.

\section{Key words}

Human papillomavirus, Vaccination, Awareness, Korea

\section{Introduction}

The prophylactic human papillomavirus (HPV) vaccine is a key component in cervical cancer control. The World Health Organization recommends the inclusion of HPV vaccines in national immunization programs [1]. Since 2007 and 2008, quadrivalent and bivalent HPV vaccines have been approved for use in South Korea. However, there had been no national or governmental HPV vaccination program, such as organized school-based vaccination or subsidized vaccination programs, until 2016. Thus, the vaccine coverage during this period was low (12\% among adult women [2]; $1 \%-10 \%$ among high school girls [3-6]). Moreover, awareness regarding HPV vaccination and its effectiveness, which is an important factor that influences the voluntary reception of the vaccination, was low among adult men and women [7], mothers [5,8], high-school girls [3,4], and college students $[9,10]$.

Since June 2016, HPV vaccination has been included in the 
fully funded National Immunization Program in Korea. The quadrivalent and bivalent HPV vaccines have also been included in the National HPV vaccination program, to be administered in 2 doses, to 12-year-old girls [11]. Furthermore, as one of the " 10 codes for cancer prevention in Korea," HPV vaccination has been recommended for cervical cancer prevention at the national level. The successful introduction and acceptance of the vaccine depends on a range of factors, including the awareness of the importance of HPV infection in cervical cancer, awareness of the use of vaccination as a preventive method, affordability of the vaccine, acceptability of the vaccine among groups, and the feasibility of delivery strategies [12].

Thus, assessing the level of awareness regarding the importance of HPV infection and vaccination among adults in Korea is necessary to predict the success of the national HPV vaccination program, as well as to measure the impact of previous educational campaigns. Therefore, we analyzed and compared data from nationwide population-based interview surveys conducted in 2007, when the HPV vaccination was introduced in Korea, and in 2016, when the HPV vaccination was included in the national routine vaccination program.

\section{Materials and Methods}

The first survey on the awareness of the HPV vaccination was conducted in November 2007 and the main results have been previously published [7]. Briefly, 1,000 randomly selected men and women over the age of 20 years in 15 of the 16 provinces in Korea responded to a face-to-face interview survey performed by trained interviewers, using a structured questionnaire. The second survey was conducted between July 5, 2016, and August 4, 2016, and involved 1,200 randomly selected men and women over the age of 20 years in the 16 provinces. The target households were randomly sampled from each district, considering the total population number, as well as the age and sex distribution in each district and province.

The second survey employed the same questionnaire used in the first survey. Participants were asked about their awareness of HPV infections, as a primary cause of cervical cancer, and their awareness of the prevention of cervical cancer via HPV vaccination. To understand the subjects' attitudes toward HPV vaccination, questions focused on five concepts were adapted from the Health Belief Model: perceived susceptibility to HPV infection, perceived severity of HPV infection, perceived benefits of HPV vaccination, perceived barriers to HPV vaccination, and cues to action for HPV vac- cination [13]. Questions on the perceived benefits included the respondent's willingness to vaccinate themselves and their children against HPV. A second questionnaire was added to the survey, regarding the awareness of the national HPV vaccination program, targeting 12-year-old girls that commenced in June 2016. General demographic characteristics including age, sex, place of residence, level of education, occupation, and family income were also collected.

Categorical variables are presented as numbers or percentages, and differences in distributions were evaluated using the Cochrane Mantel-Haenszel chi-square test with adjustment for age group. Logistic regression analysis was used to evaluate the association between the acceptance of the HPV vaccination, and related factors such as age (20-29, 30-39, 40-49, and 50 years or older), sex, residence (metropolitan area, city, and country), education (primary school or less, middle school, high school, and college or more), and family income ("low" for family incomes less than 2,000 US dollars, "middle" for incomes between 2,000 and 4,000 US dollars, and "high" for incomes greater than 4,000 US dollars); the odds ratios (ORs) and 95\% confidence intervals (CIs) were calculated. All analyses were performed using SAS ver. 9.3 (SAS Institute Inc., Cary, NC).

This study was approved by the ethics committee of the National Cancer Center in Korea (IRB Nos. NCCNCS-07-102, NCC2016-0153).

\section{Results}

Table 1 shows the general characteristics of the respondents. The sex and regional distributions were similar in the 2007 and 2016 surveys. The respondents in the 2016 survey were more likely to be older, have higher education, and be an office worker compared to the respondents in the 2007 survey, reflecting an aging population.

Table 2 shows the differences in awareness of and attitudes regarding HPV infection and vaccination between the 2007 and 2016 surveys. The awareness of the importance of HPV infection (35.8\% in 2016) and vaccination (36.9\% in 2016) were significantly increased from that in $2007(13.3 \%$ and $8.6 \%$, respectively) ( $p<0.001)$. The proportion of respondents who reported being invulnerable to HPV infection increased from $28.2 \%$ in 2007 , to $42.0 \%$ in 2016 . On the other hand, the proportion of respondents who reported being unsure of their vulnerability (52.3\% in 2007, 37.3\% in 2016) had decreased since 2007. The proportion of respondents who considered HPV infection as non-serious had increased from $8.0 \%$ to $23.7 \%$ since 2007, whereas the proportion of respondents who were uncertain about the seriousness of HPV had decreased 
Table 1. General characteristics of the respondents in the 2007 and 2016 surveys

\begin{tabular}{|c|c|c|}
\hline \multirow{2}{*}{ Characteristic } & \multicolumn{2}{|c|}{ Survey year } \\
\hline & 2007 & 2016 \\
\hline \multicolumn{3}{|l|}{ Sex } \\
\hline Men & $496(49.6)$ & $594(49.5)$ \\
\hline Women & $504(50.4)$ & $606(50.5)$ \\
\hline \multicolumn{3}{|l|}{ Age (yr) } \\
\hline $20-29$ & $222(22.2)$ & $196(16.3)$ \\
\hline $30-39$ & $239(23.9)$ & $243(20.3)$ \\
\hline $40-49$ & $225(22.5)$ & $268(22.3)$ \\
\hline$\geq 50$ & $314(31.4)$ & $493(41.1)$ \\
\hline \multicolumn{3}{|l|}{ Education } \\
\hline Middle school or less & $195(19.5)$ & $76(6.3)$ \\
\hline High school & $459(45.9)$ & $502(41.8)$ \\
\hline College or more & $345(34.5)$ & $622(51.8)$ \\
\hline \multicolumn{3}{|l|}{ Occupation } \\
\hline Agriculture/Forestry/Fishery & $39(3.9)$ & $3(0.3)$ \\
\hline Self-employment & $217(21.7)$ & $152(12.7)$ \\
\hline Clerk/Sale & $117(11.7)$ & $205(17.1)$ \\
\hline Engineer/Driver & $57(5.7)$ & $74(6.2)$ \\
\hline Janitor / Cleaner / Construction worker & $20(2.0)$ & $27(2.2)$ \\
\hline Office worker & $141(14.1)$ & $325(27.1)$ \\
\hline Professional/Manager & $9(0.9)$ & $32(2.7)$ \\
\hline House wife & $274(27.4)$ & $279(23.2)$ \\
\hline Student & $68(6.8)$ & $64(5.3)$ \\
\hline Unemployment & $58(5.8)$ & $39(3.2)$ \\
\hline \multicolumn{3}{|l|}{ Household income per month ${ }^{\text {a) }}$} \\
\hline Low & $232(23.2)$ & $236(19.7)$ \\
\hline Middle & $562(56.2)$ & $685(57.1)$ \\
\hline High & $197(19.7)$ & $279(23.2)$ \\
\hline \multicolumn{3}{|l|}{ Region } \\
\hline Metropolitan area & $479(47.9)$ & $542(45.2)$ \\
\hline City & $421(42.1)$ & $523(43.6)$ \\
\hline Country & $100(10.0)$ & $135(11.2)$ \\
\hline
\end{tabular}

Values are presented as number (\%). a)Income categorized in low ( $<2,000$ USD), middle (2,000-4,000 USD), and high ( $>4,000$ USD) in 2007; low (<3,000 USD), middle (3,000-5,000 USD), and high (> 5,000 USD) in 2016; 1 US dollar=1,000 Korean won.

from $59.5 \%$ to $37.3 \%$ since 2007 . In addition, the willingness to be vaccinated against HPV decreased from $55.0 \%$ in 2007 to $25.8 \%$ in 2016; the proportion of those who responded with uncertainty increased from $28.3 \%$ in 2007 to $43.3 \%$ in 2016 . The most common reason for refusal of vaccination was the unimportance attached to its practice ( $47 \%$ ), followed by the lack of its awareness $(32.7 \%)$, high cost $(13.7 \%)$, uncertainty about its effectiveness $(11.4 \%)$, and subsequent adverse reactions (9.9\%). In addition, the willingness of some respondents to vaccinate their daughters $(77.0 \%$ in $2007,69.5 \%$ in 2016) and sons $(73.2 \%$ in $2007,58.3 \%$ in 2016) had decreased over the years. Among respondents who were willing, $2.7 \%$ and $0.8 \%$ had already vaccinated their daughters or sons, respectively. Only $12.1 \%$ of men and $22.0 \%$ of women knew about the free national HPV vaccination program for girls launched in June 2016.

Table 3 shows the factors associated with the willingness of respondents to vaccinate themselves and their daughters, in the 2016 survey. In women, a higher willingness to be vaccinated was associated with younger age, higher income level, awareness of the HPV vaccine (adjusted OR, 1.3; 95\% CI, 1.0 to 1.8), and perception of the seriousness of infection (adjusted OR, 2.4; 95\% CI, 1.6 to 3.4). In addition, a high level of education, awareness of the importance of HPV infection (OR, 1.5; 


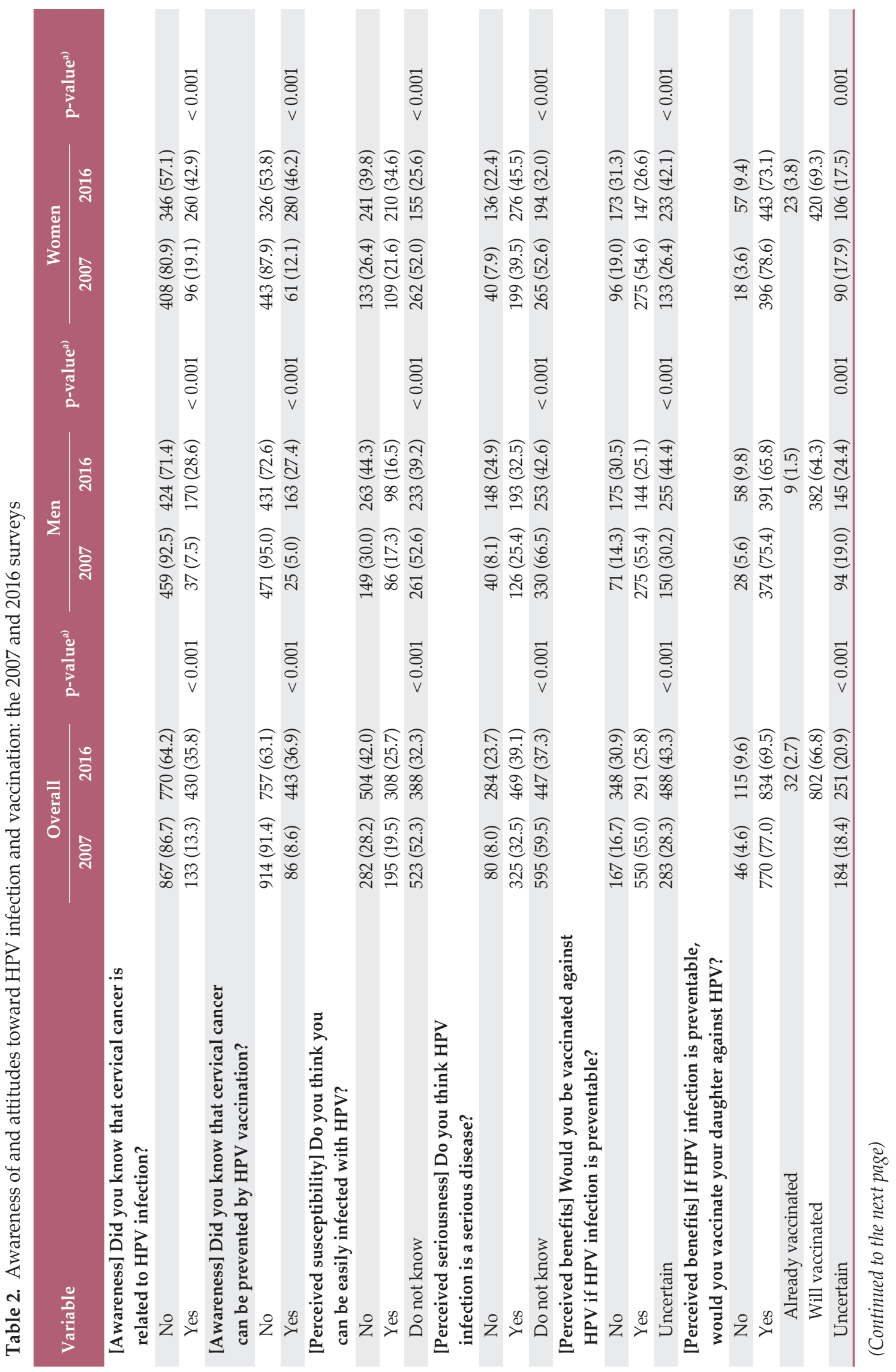




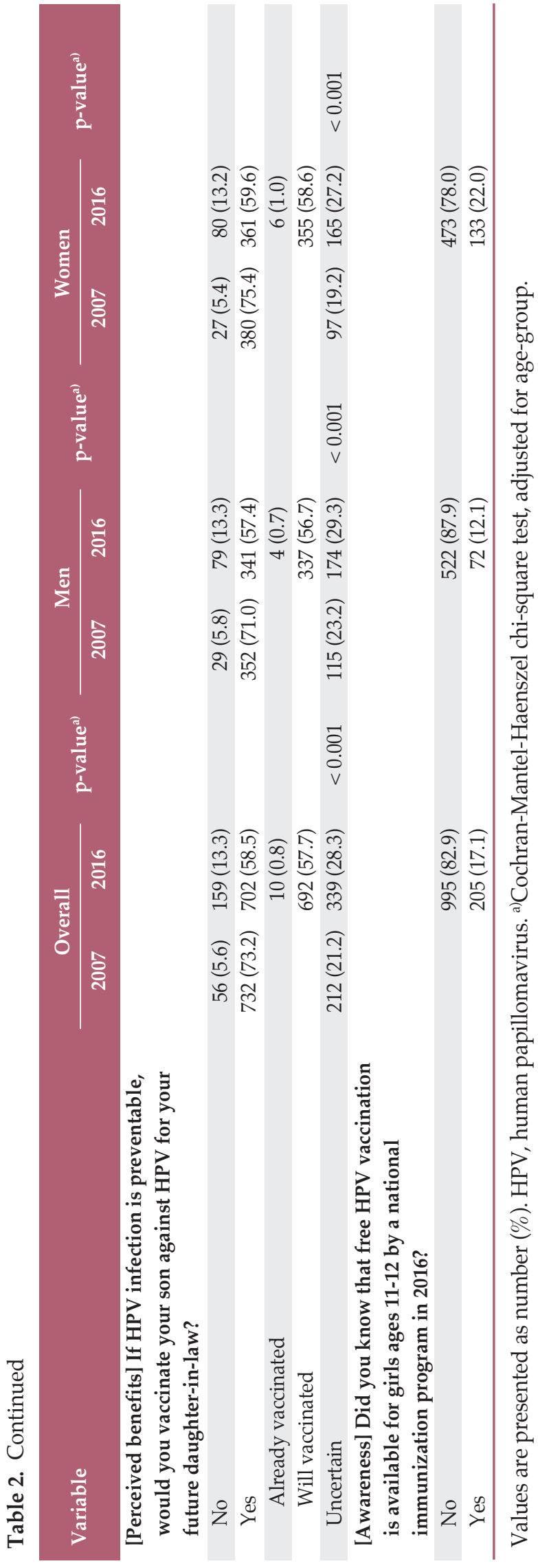

$95 \% \mathrm{CI}, 1.2$ to 2.0$)$, awareness of the vaccination (OR, $1.7 ; 95 \%$ CI, 1.3 to 2.2), and perception of the seriousness of infection (OR, 2.5; 95\% CI, 1.8 to 3.4 ) were positively associated with the respondents' willingness to vaccinate their daughters. Furthermore, women (adjusted OR, 1.5; 95\% CI, 1.1 to 1.9) had a higher willingness to vaccinate their daughters compared to men.

Additionally, only $17 \%$ of the respondents (12.1\% of men, $22.0 \%$ of women) knew about the national HPV vaccination program launched in June 2016. Women (OR, 2.3; 95\% CI, 1.7 to 3.1) and respondents aged $40-49$ years (OR, $1.8 ; 95 \% \mathrm{CI}, 1.2$ to 2.7) with a high level of education (OR, $4.3 ; 95 \%$ CI, 1.5 to 12.5 in the level of college or more compared to the level of middle school or less), awareness of HPV infection as a risk factor for cervical cancer (OR, 2.3; 95\% CI, 1.7 to 3.2), and awareness of the vaccination (OR, 3.5; 95\% CI, 2.5 to 4.9 ) were more likely to know about the National HPV Vaccination Program (Table 4).

\section{Discussion}

The incidence and mortality rates for cervical cancer have been decreasing steadily (age-standardized incidence rate, 16.3 per 100,000 women in 1999 and 9.5 in 2013; 5-year relative survival rate, $77.5 \%$ in $1993-1995$ and $80.1 \%$ in $2009-2013$ [14]), partly due to organized cervical cancer screenings [15]. However, cervical cancer is still one of the 10 major female cancers in Korea. In 2014, 3,500 new cases were diagnosed and 967 women died from cervical cancer [16].

As well known, cervical cancer can be avoided through the prevention of HPV infections. Therefore, since 2007, safe sexual behavior has been promoted as one of the 10 codes for cancer prevention in Korea, thereby, preventing cervical cancer development via the prevention of the sexual transmission of an HPV infection. Within the same period, HPV vaccines were introduced and used in Korea, but without an organized immunization program. Thus, vaccine coverage was low due to a lack of awareness of the HPV infection and vaccination, as well as the cost of vaccination [7]. Subsequently, the promotion of HPV vaccination by the private sector decreased the cost of vaccination; however, this did not substantially increase vaccine coverage. According to the Korean National Immunization Survey, vaccination coverage in 2013 was $28.7 \%, 15.9 \%$, and $4.6 \%$ among women aged 19-26 years, 27-39 years, and 40-59 years, respectively [2]. Although there is no national data on vaccine coverage in young girls, several studies have demonstrated low rates among high school girls (1\%-10\%) [3-6]. Given that HPV is a cause of cervical cancer, and a safe and effective vaccine is 
Table 3. Willingness to vaccinate oneself and respondent's daughter(s) against HPV by selected characteristics, 2016

\begin{tabular}{|c|c|c|c|c|c|c|c|}
\hline \multirow{3}{*}{ Characteristic } & \multirow{3}{*}{ Total } & \multicolumn{3}{|c|}{ Willingness to vaccinate oneself ${ }^{\text {a) }}$} & \multicolumn{3}{|c|}{ Willingness to vaccinate daughter } \\
\hline & & \multirow{2}{*}{ No. $(\%)$} & \multicolumn{2}{|c|}{ Adjusted OR (95\% CI) } & \multirow{2}{*}{ No. $(\%)$} & \multicolumn{2}{|c|}{ Adjusted OR $(95 \% \mathrm{CI})$} \\
\hline & & & Model 1 ${ }^{\text {b) }}$ & Model 2c) & & Model 1 ${ }^{\mathrm{b})}$ & Model $2^{c}$ \\
\hline \multicolumn{8}{|l|}{ Sex } \\
\hline Men & 594 & $144(25.1)$ & 1 & 1 & $391(65.8)$ & 1 & 1 \\
\hline Women & 606 & $147(26.6)$ & $1.1(0.9-1.5)$ & $1.1(0.9-1.5)$ & $443(73.1)$ & $1.4(1.1-1.8)$ & $1.5(1.1-1.9)$ \\
\hline \multicolumn{8}{|l|}{ Age (yr) } \\
\hline$\geq 50$ & 493 & $101(21.3)$ & 1 & 1 & $342(69.4)$ & 1 & 1 \\
\hline $40-49$ & 268 & $70(27.8)$ & $1.4(1.0-2.0)$ & $1.4(1.0-2.0)$ & $189(70.5)$ & $1.1(0.8-1.5)$ & $1.0(0.7-1.4)$ \\
\hline $30-39$ & 243 & $65(29.3)$ & $1.5(1.1-2.2)$ & $1.5(1.0-2.2)$ & $170(70.0)$ & $1.1(0.8-1.5)$ & $1.0(0.7-1.4)$ \\
\hline \multirow[t]{2}{*}{$20-29$} & 196 & $55(30.7)$ & $1.7(1.1-2.4)$ & $1.6(1.1-2.5)$ & $133(67.9)$ & $1.0(0.7-1.4)$ & $0.9(0.6-1.3)$ \\
\hline & & & $\mathrm{p}$-trend $=0.004$ & $\mathrm{p}$-trend $=0.009$ & & p-trend $=0.926$ & p-trend $=0.637$ \\
\hline \multicolumn{8}{|l|}{ Education } \\
\hline Middle school or less & 76 & $16(21.1)$ & 1 & 1 & $43(56.6)$ & 1 & 1 \\
\hline High school & 502 & $119(25.1)$ & $1.1(0.6-2.0)$ & $1.1(0.6-2.0)$ & $363(72.3)$ & $2.2(1.3-3.7)$ & $2.2(1.3-3.7)$ \\
\hline \multirow[t]{2}{*}{ College or more } & 622 & $156(27.1)$ & $1.1(0.6-2.0)$ & $1.1(0.6-2.0)$ & $428(68.8)$ & $2.0(1.2-3.3)$ & $2.0(1.2-3.3)$ \\
\hline & & & $\mathrm{p}$-trend $=0.821$ & $\mathrm{p}$-trend $=0.821$ & & p-trend $=0.308$ & p-trend $=0.308$ \\
\hline \multicolumn{8}{|l|}{ Income per month } \\
\hline Low $(<3,000$ USD $)$ & 236 & $46(20.1)$ & 1 & 1 & $160(67.8)$ & 1 & 1 \\
\hline Middle (3,000-5,000 USD) & 685 & $168(26.3)$ & $1.3(0.9-1.9)$ & $1.4(0.9-2.0)$ & $469(68.5)$ & $1.1(0.8-1.5)$ & $0.9(0.7-1.3)$ \\
\hline \multirow[t]{2}{*}{ High $(>5,000$ USD) } & 279 & $77(29.8)$ & $1.6(1.0-2.4)$ & $1.7(1.1-2.6)$ & $205(73.5)$ & $1.3(0.9-2.0)$ & $1.2(0.8-1.9)$ \\
\hline & & & $\mathrm{p}$-trend $=0.030$ & p-trend $=0.026$ & & p-trend $=0.126$ & p-trend $=0.205$ \\
\hline \multicolumn{8}{|l|}{ Region } \\
\hline Metropolitan area & 542 & $135(26.5)$ & 1 & 1 & $376(69.4)$ & 1 & 1 \\
\hline Middle/Small city & 523 & $132(26.8)$ & $1.0(0.8-1.3)$ & $1.0(0.8-1.3)$ & $371(70.9)$ & $1.1(0.8-1.4)$ & $1.0(0.8-1.4)$ \\
\hline \multirow[t]{2}{*}{ Small town } & 135 & $24(19.4)$ & $0.7(0.4-1.1)$ & $0.7(0.4-1.1)$ & $87(64.4)$ & $0.8(0.5-1.2)$ & $0.7(0.5-1.1)$ \\
\hline & & & $\mathrm{p}$-trend $=0.306$ & p-trend $=0.297$ & & $\mathrm{p}$-trend $=0.536$ & p-trend $=0.491$ \\
\hline \multicolumn{8}{|c|}{$\begin{array}{l}\text { Awareness of HPV infection as } \\
\text { a risk factor of cervical cancer }\end{array}$} \\
\hline No & 770 & $185(24.4)$ & 1 & 1 & $507(65.8)$ & 1 & 1 \\
\hline Yes & 430 & $106(28.7)$ & $1.2(0.9-1.6)$ & $1.2(0.9-1.6)$ & $327(76.1)$ & $1.6(1.2-2.1)$ & $1.5(1.2-2.0)$ \\
\hline \multicolumn{8}{|l|}{ Awareness of HPV vaccine } \\
\hline No & 757 & $173(23.7)$ & 1 & 1 & $493(65.1)$ & 1 & 1 \\
\hline Yes & 443 & $118(29.8)$ & $1.3(1.0-1.8)$ & $1.3(1.0-1.8)$ & $341(77.0)$ & $1.8(1.3-2.2)$ & $1.7(1.3-2.2)$ \\
\hline \multicolumn{8}{|l|}{ Perceived seriousness } \\
\hline No & 284 & $47(17.5)$ & 1 & 1 & $172(60.6)$ & 1 & 1 \\
\hline Yes & 469 & $145(33.6)$ & $2.4(1.6-3.4)$ & $2.4(1.6-3.4)$ & $375(80.0)$ & $2.5(1.8-3.5)$ & $2.5(1.8-3.4)$ \\
\hline Do not know & 447 & $99(23.2)$ & $1.4(1.0-2.1)$ & $1.4(1.0-2.1)$ & $287(64.2)$ & $1.2(0.9-1.6)$ & $1.2(0.9-1.6)$ \\
\hline \multicolumn{8}{|l|}{ Awareness on NHPVP } \\
\hline No & 995 & $239(25.1)$ & 1 & 1 & $682(68.5)$ & 1 & 1 \\
\hline Yes & 205 & $52(29.9)$ & $1.2(0.8-1.7)$ & $1.2(0.8-1.7)$ & $152(74.2)$ & $1.2(0.9-1.8)$ & $1.2(0.9-1.7)$ \\
\hline
\end{tabular}

HPV, human papillomavirus; OR, odds ratio; CI, confidence interval; NHPVP, National HPV Vaccination Program. ${ }^{\text {a)The }}$ willingness to vaccinate oneself was analyzed except for 73 persons who had already received HPV vaccination before the

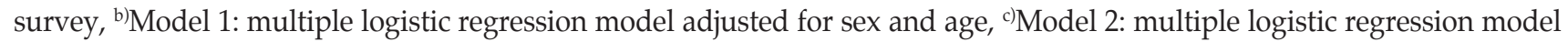
adjusted for sex, age, and education, when appropriate.

available, the most effective target population is young girls without any sexual experience. Thus, in 2016, the Korean government, as a part of the National Immunization Pro- gram, offered a fully funded HPV vaccination opportunity to girls aged 12 years [11]. Therefore, it is very important to assess the awareness of the HPV infection and vaccination in 
Table 4. Awareness of the national HPV vaccination program by selected characteristics, 2016

\begin{tabular}{|c|c|c|c|c|}
\hline \multirow{3}{*}{ Characteristic } & \multirow{3}{*}{ Total } & \multicolumn{3}{|c|}{ Awareness of the National HPV Vaccination Program } \\
\hline & & \multirow{2}{*}{ No. $(\%)$} & \multicolumn{2}{|c|}{ Adjusted OR (95\% CI) } \\
\hline & & & Model 1 $1^{\text {a) }}$ & Model 2 ${ }^{\text {b) }}$ \\
\hline \multicolumn{5}{|l|}{ Sex } \\
\hline Men & 594 & $72(12.1)$ & 1 & 1 \\
\hline Women & 606 & $133(21.9)$ & $2.1(1.6-2.9)$ & $2.3(1.7-3.1)$ \\
\hline \multicolumn{5}{|l|}{ Age (yr) } \\
\hline$\geq 50$ & 493 & $61(12.4)$ & 1 & 1 \\
\hline $40-49$ & 268 & $58(21.6)$ & $2.1(1.4-3.1)$ & $1.8(1.2-2.7)$ \\
\hline 30-39 & 243 & $47(19.3)$ & $1.8(1.2-2.7)$ & $1.4(0.9-2.2)$ \\
\hline $20-29$ & 196 & $39(19.9)$ & $1.9(1.2-3.0)$ & $1.4(0.9-2.3)$ \\
\hline & & & $\mathrm{p}$-trend $=0.002$ & p-trend $=0.130$ \\
\hline \multicolumn{5}{|l|}{ Education } \\
\hline Middle school or less & 76 & $4(5.3)$ & 1 & 1 \\
\hline High school & 502 & $74(14.7)$ & $2.9(1.0-8.4)$ & $2.9(1.0-8.4)$ \\
\hline \multirow[t]{2}{*}{ College or more } & 622 & $127(20.4)$ & $4.3(1.5-12.5)$ & $4.3(1.5-12.5)$ \\
\hline & & & p-trend $<0.001$ & p-trend $<0.001$ \\
\hline \multicolumn{5}{|l|}{ Income per month } \\
\hline Low $(<3,000$ USD) & 236 & $35(14.8)$ & 1 & 1 \\
\hline Middle (3,000-5,000 USD) & 685 & $119(17.4)$ & $1.1(0.7-1.7)$ & $0.9(0.6-1.4)$ \\
\hline \multirow[t]{2}{*}{ High (> 5,000 USD) } & 279 & $51(18.3)$ & $1.2(0.7-1.9)$ & $0.9(0.5-1.4)$ \\
\hline & & & $\mathrm{p}$-trend $=0.422$ & p-trend $=0.720$ \\
\hline \multicolumn{5}{|l|}{ Region } \\
\hline Metropolitan area & 542 & $81(14.9)$ & 1 & 1 \\
\hline Middle/Small city & 523 & $103(19.7)$ & $1.4(1.0-2.0)$ & $1.4(1.0-1.9)$ \\
\hline \multirow[t]{2}{*}{ Small town } & 135 & $21(15.6)$ & $1.0(0.6-1.8)$ & $1.0(0.6-1.7)$ \\
\hline & & & $\mathrm{p}$-trend $=0.226$ & $\mathrm{p}$-trend $=0.324$ \\
\hline \multicolumn{5}{|c|}{$\begin{array}{l}\text { Awareness of HPV infection as } \\
\text { a risk factor of cervical cancer }\end{array}$} \\
\hline No & 770 & $90(11.7)$ & 1 & 1 \\
\hline Yes & 430 & $115(26.7)$ & $2.4(1.7-3.3)$ & $2.3(1.7-3.2)$ \\
\hline \multicolumn{5}{|l|}{ Awareness of HPV vaccine } \\
\hline No & 757 & $73(9.6)$ & 1 & 1 \\
\hline Yes & 443 & $132(29.8)$ & $3.6(2.6-4.9)$ & $3.5(2.5-4.9)$ \\
\hline \multicolumn{5}{|l|}{ Perceived seriousness } \\
\hline No & 284 & $44(15.5)$ & 1 & 1 \\
\hline Yes & 469 & $101(21.5)$ & $1.4(0.9-2.1)$ & $1.4(0.9-2.0)$ \\
\hline Do not know & 447 & $60(13.4)$ & $0.9(0.6-1.4)$ & $0.9(0.6-1.4)$ \\
\hline
\end{tabular}

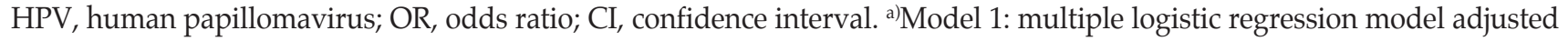

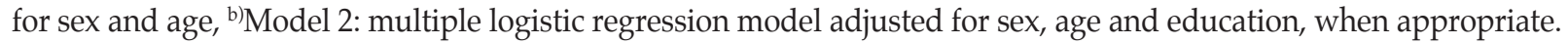

the general population, which are possible key factors affecting the acceptance of HPV vaccination.

The results of the present study demonstrate that among adults, the awareness of HPV infection as a risk factor for cervical cancer has increased since 2007. In addition, the awareness of HPV vaccination as a preventive measure for cervical cancer has increased since 2007, while the willingness of respondents to vaccinate themselves or their daughter(s) against HPV has decreased since 2007 [7]. One possible explanation for these findings is that an awareness has been raised by the government sector, through the dissemination of information regarding the modes of acquisition of the HPV infection, as well as the promotion of HPV testing and vaccination in the private sectors. Furthermore, available 
information on HPV-related issues has improved knowledge; this has reduced uncertainty and misconceptions. Among adults, correct knowledge and an improved awareness of the HPV vaccination may decrease willingness to vaccinate themselves against HPV. Many sources, including the National Cancer Information Center (http://www.cancer. go.kr) and the Centers for Disease Control \& Prevention (http://nip.cdc.go.kr), continually provide reliable detailed information regarding HPV infections, cervical cancer, and the HPV vaccine. The information emphasizes the higher effectiveness of the HPV vaccine in young girls compared to middle-aged women and men. The most common reason for refusal of the HPV vaccination in the present study was the perception of some respondents that the vaccine was not necessary for them. However, men and women with a higher educational level, greater knowledge regarding HPV infection and vaccination, and greater perception of the seriousness of HPV infections had a high willingness for vaccination and were more likely to vaccinate their daughter(s) against HPV.

The results of the present study demonstrate that the overall awareness of the national HPV vaccination program is still very low; however, the awareness of the newly launched national HPV vaccination program was relatively higher in women with high educational level, and awareness of HPV infection and vaccination. Respondents aged 40-49 years reflect an age group with a high probability of having young daughters around 12 years; these were also more likely to know about the national HPV vaccination program, compared to respondents in other age groups. Other evaluated factors did not have a significant effect on the awareness of the national HPV vaccination program. To encourage HPV vaccination among young girls around 12 years of age, it appears to be necessary for the parents of these girls to receive more information regarding the national HPV vaccination program, including why a high priority is placed on this target population, for HPV vaccination, with regard to cervical cancer prevention.

A strength of this study is that data from two nationwide surveys with the same design were used, allowing easy observation of changes in awareness and acceptance of the HPV vaccination over time. The present study also has several limitations. First, the relatively small sample sizes $(1,000-$ 1,200 respondents) are not adequate to be representative of the general population in Korea. However, we randomly sampled respondents proportional to size of the population, from 16 provinces (15 provinces in 2007) across the country, who reflected the age and sex distribution in each district and province. As a result, the general characteristics of the respondents are similar to those of the Korean general population. Second, the present study did not include children or adolescents, even though they are the targeted group for HPV vaccination. Further studies on awareness and acceptance of HPV vaccination among various groups including adolescents, parents, teachers, and health professionals are needed.

In conclusion, raising the awareness of HPV infection and vaccination with the appropriate knowledge is necessary for the successful implementation of the national HPV vaccination program. Further promotion and awareness of the national HPV vaccination program could be expected to increase the vaccine coverage, which may guarantee a cervical-cancer-free generation in the future of Korea.

\section{Conflicts of Interest}

Conflict of interest relevant to this article was not reported.

\section{Acknowledgments}

This study was financially supported by the Ministry of Health and Welfare (1660660) and partly supported by the National Cancer Center (NCC-1610410).

\section{References}

1. Human papillomavirus vaccines: WHO position paper, October 2014. Wkly Epidemiol Rec. 2014;89:465-91.

2. Lee SG, Jeon SY, Park O, Kim MY, Yang HI, Park EY. Vaccination coverage of adults aged above 19 years using mixedmode random digit dialing (RDD) survey. J Korean Soc Matern Child Health. 2015;19:58-70.

3. Kang HS, Moneyham L. Attitudes, intentions, and perceived barriers to human papillomavirus vaccination among Korean high school girls and their mothers. Cancer Nurs. 2011;34:
202-8.

4. Lee YE, Park JS, Choi EJ. The exact state of female high school students' knowledge about cervical cancer, human papillomavirus vaccination-related health belief and vaccination rate. J Korean Soc Matern Child Health. 2013;17:27-37.

5. Yoo MS. Knowledge level of human papillomavirus, cervical cancer and vaccination status among mothers with daughters in high school. Korean J Women Health Nurs. 2014;20:105-14.

6. Choi MS, Cheon S. HPV (human papillomavirus) vaccination 
coverage and intention among female middle and high school students. J Korean Soc Living Environ Syst. 2015;22:93-105.

7. Oh JK, Lim MK, Yun EH, Lee EH, Shin HR. Awareness of and attitude towards human papillomavirus infection and vaccination for cervical cancer prevention among adult males and females in Korea: a nationwide interview survey. Vaccine. 2010;28:1854-60.

8. Kim JS, Kang HY. Mothers' knowledge, health beliefs and intentions to vaccinate their daughters against human papillomavirus in Korea. Contemp Nurse. 2014;47:97-107.

9. Kang HY, Kim JS. Knowledge, attitudes of human papillomavirus vaccine, and intention to obtain vaccine among Korean female undergraduate students. Women Health. 2011;51:759-76.

10. Lee EJ, Park JS. Knowledge about cervical cancer, health beliefs and human papillomavirus vaccination rate in female university students. J Korean Oncol Nurs. 2011;11:65-73.

11. Korean Centers for Disease Control and Prevention. Guidelines for the National Immunization Program [Internet].
Cheongju: Korean Centers for Disease Control and Prevention; 2017 [cited 2017 Jan 6]. Available from: https://nip.cdc.go.kr.

12. Graham JE, Mishra A. Global challenges of implementing human papillomavirus vaccines. Int J Equity Health. 2011; 10:27.

13. Glanz K, Rimer BK, Lewis FM. Health behavior and health education: theory, research, and practice. San Francisco, CA: Jossey-Bass; 2002.

14. Oh CM, Won YJ, Jung KW, Kong HJ, Cho H, Lee JK, et al. Cancer statistics in Korea: incidence, mortality, survival, and prevalence in 2013. Cancer Res Treat. 2016;48:436-50.

15. Jun JK, Choi KS, Jung KW, Lee HY, Gapstur SM, Park EC, et al. Effectiveness of an organized cervical cancer screening program in Korea: results from a cohort study. Int J Cancer. 2009;124:188-93.

16. National Cancer Information Center. Cancer statistics in 2014, Korea [Internet]. Goyang: National Cancer Information Center; 2016 [cited 2016 Dec 20]. Available from: http://www.cancer.go.kr. 